\title{
Association between Physical Activity and Cognitive Dysfunction in the Korean: A Cross-sectional Study
}

\author{
Sanghoon, Jeong ${ }^{1}$, Jae Yong Jang ${ }^{2^{*}}$ \\ 'Department of Marine Sports, Pukyong National University, Busan, Republic of Korea \\ ${ }^{2}$ Department of Ocean Physical Education, College of Ocean Science and Technology, Korea Maritime \& Ocean University, Busan, \\ Republic of Korea
}

\begin{abstract}
OBJECTIVES: This study aimed to investigate the association of physical activity and cognitive function in the Korean population.

METHODS: This study included 9,177 adults aged 45 years and older who completed the baseline survey of the Korean Longitudinal Study of Ageing. Physical activity was assessed using a questionnaire. Cognitive function was assessed using the Mini Mental Status Evaluation.

RESULTS: The odds ratio for the cognitive dysfunction was significantly and linearly decreased according to the levels of physical activity independent of confounding factors. We also found consistent results when investigated these associations using stratified model by sex and age groups.

CONCLUSIONS: Our findings suggest that physical activity is associated with lower risk of cognitive dysfunction in the middle-aged and older Korean adults.

\section{KEY WORDS: Physical activity; Exercise; Cognitive function}

(C) The Author(s). 2017 Open Access This is an open-access article distributed under the terms of the Creative Commons Attribution License (http://creativecommons.org/licenses/by/4.0/), which permits unrestricted use, distribution, and reproduction in any medium, provided the original work is properly cited.
\end{abstract}

\section{INTRODUCTION}

Dementia is a major health problem in the elderly with estimated 46.8 million people affected worldwide in 2015 . The prevalence of dementia is also estimated to be close to 50 million people in 2017 and to double every 20 years, reaching 75 million in 2030 and 131.5 million in 2050 [1]. The cognitive functional decline is observed in most elderly people. Previous epidemiological studies suggested that cognitive decline is associated with development of dementia. Annually, 10-15\% of older people with mild cognitive impairment progress to dementia compared with $1-2 \%$ of older people with normal cognition $[2,3]$.

\footnotetext{
*Correspondence: Jae Yong Jang（jjy80@kmou.ac.kr）

Department of Ocean Physical Education, College of Ocean Science and Technology, Korea Maritime \& Ocean University, Busan, Republic of Korea Received: July 31, 2017; Accepted: September 25, 2017;

Published: September 28, 2017
}

Previous studies suggests that higher physical activity are associated with prevention of the decline in cognitive function and reduced risk of dementia with aging [4-6]. In addition, changes in physical activity may contribute to age-related changes in biological vitality and physical function. Moreover, higher levels of physical activity is associated with a decreased risk of cardiovascular disease, all-cause and cardiovascular mortality, physical function decline, and frailty [7-10]. Therefore, physical activity may also have an effect on the risk of cognitive dysfunction.

Previous studies have investigated the association between physical activity and cognitive functions. However, only a few examined the associations between physical activity and cognitive function in the Korean population. Additionally, to our knowledge, physical activity level recommended by current guidelines for Korean adults has not been reported as a potential predictor of cognitive 
dysfunction in the older Korean adults. Therefore, we aimed to investigate whether physical activity is associated with the risk of cognitive dysfunction in the elderly Korean population.

\section{METHODS}

\section{Study Participants}

The present study used the data from the Korean Longitudinal Study of Ageing (KLoSA), a national survey of adults aged $\geq 45$ years [11]. The KLoSA was started in August 2006, and 10,254 subjects completed the baseline survey interview using computer-assisted personal interviewing method. In this study, we selected 4,165 participants aged $\geq 45$ years, and 1,077 subjects were excluded due to missing data for physical activity, cognitive function score, and other covariates. For this analysis, a total of 9,177 subjects were included. All subjects provided written informed consent, and the study protocol was approved by the Institutional Review Board of the Korea Employment Information Service.

\section{Assessment of Physical Activity}

The total volume of physical activity was assessed using a questionnaire. All subjects were asked to record the frequency of physical activity (times per week) and duration (min). Time spent being physically active was calculated considering frequency and duration in minutes per week. The subjects were categorized into three groups by total physical activity time: inactive (none), $<150 \mathrm{~min}$ per week, and $\geq 150$ min per week based on the current physical activity guidelines for Korean adults [7,12].

\section{Cognitive Function}

Cognitive function was assessed using the Korea-Mini Mental Status Evaluation (K-MMSE). The K-MMSE comprises five areas, including registration, orientation, memory, attention and calculation, and language $[13,14]$. We categorized subjects into normal cognitive (K-MMSE $\geq 24)$ and cognitive dysfunction (K-MMSE $<24)$ groups [15].

\section{Confounding Factors}

Age, sex, education level, smoking status, and medical health conditions (depression, hypertension, diabetes, cardiovascular disease, and cancer) were considered as potential confounders. We categorized education levels as $<$ high school, high school, or $>$ high school. Smoking status was defined as never, former smoking, and current smoking. Medical health conditions were assessed using self-reported questionnaire.

\section{Statistical Analysis}

We analyzed all dataset using SPSS software (PASW Statis- tics 18 for Windows, IBM Inc., Chicago, IL, USA), and the results were considered statistically significant with $\mathrm{P}$ values $<0.05$. The subjects' characteristics are expressed as mean \pm standard deviation (SD) for continuous variables and sample size (\%) for categorical variables. We analyzed the characteristics of study participants by physical activity levels using the ANOVA for continuous variables and Chi-squared tests for categorical variables. Multivariable logistic regression models were used to assess the association of physical activity levels and the risk of cognitive dysfunction. We also developed three sequential models to test the effect of confounding factors on the association between physical activity and cognitive dysfunction: 1) adjusted for age and sex; 2) additionally adjusted for education level and smoking status; 3) additionally adjusted for depression, hypertension, diabetes, cardiovascular disease, and cancer. In addition, we conducted sensitivity analysis using separated model by age group $(<65$ years and $\geq 65$ years) and sex.

\section{RESULTS}

In Table 1 , characteristics of the participants are presented. The mean age was $61.04 \pm 10.91$ years. Overall, $44.55 \%$

\begin{tabular}{|c|c|}
\hline Characteristics & Distribution \\
\hline Age (years) & $61.04 \pm 10.91$ \\
\hline Body mass index $\left(\mathrm{kg} / \mathrm{m}^{2}\right)$ & $23.48 \pm 7.61$ \\
\hline Cognitive function (K-MMSE, score) & $24.56 \pm 5.93$ \\
\hline \multicolumn{2}{|l|}{ Sex $(\%)$} \\
\hline Male & $4088 \quad(44.55)$ \\
\hline Female & $5089 \quad(55.45)$ \\
\hline \multicolumn{2}{|l|}{ Education level (\%) } \\
\hline$<$ high school & $5636 \quad(61.41)$ \\
\hline high school & $2513(27.38)$ \\
\hline >high school & $1028(11.20)$ \\
\hline \multicolumn{2}{|l|}{ Smoking status (\%) } \\
\hline Never & $6486(70.68)$ \\
\hline Former smoker & 889 (9.69) \\
\hline Current smoker & 1802 (19.64) \\
\hline \multicolumn{2}{|l|}{ Depression (\%) } \\
\hline No & 8126 (88.5) \\
\hline Yes & 1051 \\
\hline \multicolumn{2}{|l|}{ Hypertension (\%) } \\
\hline No & $6732(73.36)$ \\
\hline Yes & $2445 \quad(26.64)$ \\
\hline \multicolumn{2}{|l|}{ Diabetes (\%) } \\
\hline No & $8105 \quad(88.32)$ \\
\hline Yes & 1072 (11.68) \\
\hline \multicolumn{2}{|l|}{ CVD (\%) } \\
\hline No & 8749 (95.34) \\
\hline Yes & 428 (4.66) \\
\hline \multicolumn{2}{|l|}{ Cancer (\%) } \\
\hline No & 8958 (97.61) \\
\hline Yes & 219 (2.39) \\
\hline
\end{tabular}

Data are means \pm SD for continuous variables and sample size (\%) for categorical variables. 
Table 2. Characteristics of study participants by physical activity levels

\begin{tabular}{|c|c|c|c|c|c|c|c|}
\hline \multirow{2}{*}{$\begin{array}{l}\text { Characteristics } \\
\text { Age (years) }\end{array}$} & \multicolumn{2}{|c|}{$\begin{array}{c}\text { High } \\
(n=2552)\end{array}$} & \multicolumn{2}{|c|}{$\begin{array}{c}\text { Low } \\
(n=1002)\end{array}$} & \multicolumn{2}{|c|}{$\begin{array}{l}\text { Inactive } \\
(n=5623)\end{array}$} & \multirow{2}{*}{$\begin{array}{l}\text { P-value } \\
<0.001\end{array}$} \\
\hline & 59.51 & \pm 0.21 & 58.47 & \pm 0.34 & 62.19 & \pm 0.14 & \\
\hline Cognitive function (K-MMSE, score) & 25.93 & \pm 0.12 & 26.11 & \pm 0.18 & 23.67 & \pm 0.08 & $<0.001$ \\
\hline \multicolumn{8}{|l|}{ Cognitive dysfunction } \\
\hline No & 2126 & $(83.31)$ & 852 & $(85.03)$ & 3722 & $(66.19)$ & \multirow[t]{2}{*}{$<0.001$} \\
\hline Yes & 426 & (16.69) & 150 & $(14.97)$ & 1901 & $(33.81)$ & \\
\hline \multicolumn{8}{|l|}{$\operatorname{Sex}(\%)$} \\
\hline Male & 1244 & $(48.75)$ & 479 & $(47.80)$ & 2365 & $(42.06)$ & \multirow[t]{2}{*}{$<0.001$} \\
\hline Female & 1308 & $(51.25)$ & 523 & $(52.20)$ & 3258 & $(57.94)$ & \\
\hline \multicolumn{8}{|l|}{ Education level (\%) } \\
\hline$<$ high school & 1215 & $(47.61)$ & 480 & $(47.90)$ & 3941 & (70.09) & \multirow[t]{3}{*}{$<0.001$} \\
\hline high school & 856 & (33.54) & 353 & $(35.23)$ & 1304 & (23.19) & \\
\hline$>$ high school & 481 & (18.85) & 169 & $(16.87)$ & 378 & $(6.72)$ & \\
\hline \multicolumn{8}{|l|}{ Smoking status (\%) } \\
\hline Never & 1816 & (71.16) & 695 & $(69.36)$ & 3975 & (70.69) & \multirow[t]{3}{*}{$<0.001$} \\
\hline Former smoker & 329 & (12.89) & 123 & $(12.28)$ & 437 & (7.77) & \\
\hline Current smoker & 407 & (15.95) & 184 & $(18.36)$ & 1211 & (21.54) & \\
\hline \multicolumn{8}{|l|}{ Depression (\%) } \\
\hline No & 2292 & $(89.81)$ & 888 & $(88.62)$ & 4946 & (87.96) & \multirow[t]{2}{*}{0.051} \\
\hline Yes & 260 & (10.19) & 114 & $(11.38)$ & 677 & (12.04) & \\
\hline \multicolumn{8}{|l|}{ Hypertension (\%) } \\
\hline No & 1845 & $(72.30)$ & 750 & $(74.85)$ & 4137 & (73.57) & \multirow[t]{2}{*}{0.253} \\
\hline Yes & 707 & $(27.70)$ & 252 & $(25.15)$ & 1486 & (26.43) & \\
\hline \multicolumn{8}{|l|}{ Diabetes (\%) } \\
\hline No & 2222 & $(87.07)$ & 878 & $(87.62)$ & 5005 & $(89.01)$ & \multirow[t]{2}{*}{0.031} \\
\hline Yes & 330 & (12.93) & 124 & $(12.38)$ & 618 & (10.99) & \\
\hline \multicolumn{8}{|l|}{ CVD (\%) } \\
\hline No & 2420 & (94.83) & 957 & $(95.51)$ & 5372 & (95.54) & \multirow[t]{2}{*}{0.357} \\
\hline Yes & 132 & $(5.17)$ & 45 & $(4.49)$ & 251 & $(4.46)$ & \\
\hline \multicolumn{8}{|l|}{ Cancer (\%) } \\
\hline No & 2481 & (97.22) & 977 & $(97.50)$ & 5500 & (97.81) & \multirow[t]{2}{*}{0.256} \\
\hline Yes & 71 & $(2.78)$ & 25 & $(2.50)$ & 123 & (2.19) & \\
\hline
\end{tabular}

Data are means \pm SD for continuous variables and sample size (\%) for categorical variables.

P-values were calculated using the ANOVA for continuous variables and Chi-squared test for categorical variables.

of participants were men, and $55.45 \%$ were women. The mean cognitive function sore was $24.56 \pm 5.93$. Table 2 shows the characteristics of study participants by physical activity level. We found significant differences in age, cognitive function score, and prevalence of cognitive dysfunction (all $\mathrm{P}<0.001$, Table 2).

Table 3 shows the results of multivariable odds ratio (OR) and 95\% confidence interval (CIs) for the risk of cognitive dysfunction by physical activity levels. Levels of physical activity were significantly associated with a re- duced risk of cognitive dysfunction after adjustment for age and sex. The results were not changed after additionally adjusted for education level and smoking status. In fully adjusted model, we also found significant association between physical activity levels and cognitive dysfunction (Table 3, model 3). We also found consistent results when investigated these associations using stratified model according to sex and age group (Table 4).

Table 3. Multivariable OR $(95 \% \mathrm{Cl})$ for the risk of cognitive dysfunction by physical activity levels

\begin{tabular}{|c|c|c|c|}
\hline \multirow{2}{*}{ Physical activity } & Model 1 & Model 2 & Model 3 \\
\hline & OR $\quad(95 \% \mathrm{Cl})$ & OR $\quad(95 \% \mathrm{Cl})$ & OR $(95 \% \mathrm{Cl})$ \\
\hline Inactive $(n=5623)$ & 1.00 (reference) & 1.00 (reference) & 1.00 (reference) \\
\hline Low $(n=1002)$ & $0.48 \quad(0.43-0.55)$ & $0.56 \quad(0.49-0.64)$ & $0.55(0.48-0.63)$ \\
\hline High $(n=2552)$ & $0.44 \quad(0.36-0.54)$ & $0.50 \quad(0.41-0.62)$ & $0.49 \quad(0.40-0.60)$ \\
\hline P-for trend & $<0.001$ & $<0.001$ & $<0.001$ \\
\hline
\end{tabular}

Model 1: adjusted for age and sex.

Model 2: adjusted for age, sex, education level, and smoking status.

Model 3: adjusted for age, sex, education level, smoking status, depression, hypertension, diabetes, cardiovascular disease, and cancer. 


\begin{tabular}{|c|c|c|c|c|}
\hline Physical activity & $\mathrm{N}$ & OR $\quad(95 \% \mathrm{Cl})$ & $\mathrm{N}$ & OR $\quad(95 \% \mathrm{Cl})$ \\
\hline & \multicolumn{2}{|r|}{ Male } & \multicolumn{2}{|r|}{ Female } \\
\hline Inactive & 2365 & 1.00 (reference) & 3258 & 1.00 (reference) \\
\hline Low & 479 & $0.56 \quad(0.45-0.69)$ & 523 & $0.56 \quad(0.47-0.67)$ \\
\hline High & 1244 & $0.54 \quad(0.39-0.74)$ & 1308 & $0.47 \quad(0.36-0.61)$ \\
\hline \multirow[t]{2}{*}{$P$-for trend } & \multicolumn{3}{|c|}{$<0.001$} & $<0.001$ \\
\hline & \multicolumn{2}{|r|}{$<65$ years } & & $\geq 65$ years \\
\hline Inactive & 3248 & 1.00 (reference) & 2375 & 1.00 (reference) \\
\hline Low & 721 & $0.69 \quad(0.57-0.83)$ & 281 & $0.47 \quad(0.39-0.57)$ \\
\hline High & 1735 & $0.55 \quad(0.41-0.74)$ & 817 & $0.44 \quad(0.33-0.59)$ \\
\hline P-for trend & \multicolumn{3}{|c|}{$<0.001$} & $<0.001$ \\
\hline
\end{tabular}

Models defined in Table 3 (Model 3) were used.

\section{DISCUSSION}

In this study, we investigated the association between physical activity levels and the risk of cognitive dysfunction in the Korean population. Our findings suggest that higher level of physical activity is significantly associated with a lower risk of cognitive dysfunction independent of clinical health conditions and other potential confounding factors. Moreover, sensitivity analysis using stratified model by age group and sex also showed similar association between higher levels of physical activity and decreased risk of cognitive dysfunction. These findings suggest that low physical activity may be a risk factor for cognitive function decline in the general Korean population.

In the present study, the prevalence of cognitive dysfunction was approximately two times higher in participants with the lowest levels of physical activity compared to those with the highest physical activity levels. The present study is the first investigation that confirmed the association of physical activity and cognitive dysfunction in the middle-aged and older Korean populations. The results of our study are consistent with previous reports showing that physical activity is associated with risk of cognitive dysfunction and mild cognitive impairment [1619]. For example, a study on the community-dwelling older adults reported that daily physical activity was associated with cognitive function variability in the elderly [20]. In addition, 28-year follow-up study analyzed using Whitehall II cohort reported that lower levels of physical activity was associated with an increased risk of dementia in the elderly [21].

Biological ageing contributes to the changes in nervous system function, which could explain the association of physical activity and cognitive decline during aging process [22]. A decline in the function of the central nervous system with aging may be an important mechanism underlying the association of physical activity and cognitive dysfunction. In fact, a slow reaction is associated with decreased cognitive function in the older adults [23]. Moreover, another systematic review and meta-analysis reported a longitudinal association of physical activity and changes in cognitive abilities [19]. Thus, physical activity might contribute to prevention of age-related decrease in the central nervous system function, which is reflected in cognitive dysfunction.

Previous epidemiological studies have described the association between physical activity and cognitive dysfunction. Our results are consistent with several recent studies, in which physical activity was associated with a risk of cognitive dysfunction in the older population. However, there remains a lack of information about the effect of physical activity on the risk of cognitive dysfunction in the middle-aged population. Therefore, in this study, we also investigated the association of physical activity levels and the risk for cognitive dysfunction using stratified model, and we observed no difference between the middle-aged and older populations. These findings suggest that physically active lifestyle may prevent cognitive decline with ageing even in middle-aged adults. However, further longitudinal and intervention studies are necessary.

\section{Strengths and Limitations}

Several limitations of this study should be acknowledged. In the present study, the primary limitation is that we cannot infer causal effect of physical activity on the risk of cognitive dysfunction because of the cross-sectional design. Moreover, we assessed the total volume of physical activity but not each type, such as intensity and domain specific activity parameters, that may predict cognitive decline [24-26]. However, our study included a large nationally representative sample of Korean adults, and our analyses were considered for important confounding factors. Thus, our findings can be generalized to the Korean population. However, the level of physical activity in Koreans is still insufficient, and the amount of physical activity has been decreasing during the past decade [27]. Recently, a systematic review showed that physical activity intervention may help to improve cognitive function in the middle-aged adults [28-30]. Therefore, our findings of this 
study are important for public health strategies aimed at preventing cognitive dysfunction in the Korean population.

\section{CONCLUSIONS}

We found that higher physical activity was strongly associated with decreased risk of cognitive dysfunction in Korean adults. Further study of the prospective association of physical activity and the risk of new onset cognitive dysfunction is warranted.

\section{Conflicts of interest}

The authors declare no conflicts of interest.

\section{REFERENCES}

[1] Prince M, Guerchet M, Prina M. The epidemiology and impact of dementia: current state and future trends. Geneva: World Health Organization. 2015.

[2] Ferri CP, Prince M, Brayne C, et al. Global prevalence of dementia: a Delphi consensus study. Lancet. 2005; 366(9503):2112-2117. https://doi.org/10.1016/s0140-6736(05)67889-0

[3] Mathers CD, Loncar D. Projections of global mortality and burden of disease from 2002 to 2030. PLoS Med. 2006; 3(11):e442. https://doi.org/10.1371/journal.pmed.0030442

[4] Winblad B, Amouyel P, Andrieu S, et al. Defeating Alzheimer's disease and other dementias: a priority for European science and society. Lancet Neurol. 2016; 15(5):455-532. https://doi.org/10.1016/s1474-4422(16)00062-4

[5] Baumgart M, Snyder HM, Carrillo MC, Fazio S, Kim $\mathrm{H}$, Johns H. Summary of the evidence on modifiable risk factors for cognitive decline and dementia: A population-based perspective. Alzheimers Dement. 2015; 11(6):718-726. https://doi.org/10.1016/j.jalz.2015.05.016

[6] Ahlskog JE, Geda YE, Graff-Radford NR, Petersen RC. Physical exercise as a preventive or diseasemodifying treatment of dementia and brain aging. Mayo Clin Proc. 2011; 86(9):876-884. https://doi.org/10.4065/mcp.2011.0252

[7] Kim J. Association between meeting physical activity guidelines and mortality in Korean adults: An 8-year prospective study. J Exerc Nutrition Biochem. 2017; 21(2):23-29. https://doi.org/10.20463/jenb.2016.0054

[8] Tambalis KD, Panagiotakos DB, Georgousopoulou $\mathrm{EN}$, et al. Impact of physical activity category on incidence of cardiovascular disease: Results from the 10-year follow-up of the ATTICA Study (20022012). Prev Med. 2016; 93:27-32. https://doi.org/10.1016/j.ypmed.2016.09.023
[9] Lee IM, Shiroma EJ, Lobelo F, Puska P, Blair SN, Katzmarzyk PT. Effect of physical inactivity on major non-communicable diseases worldwide: an analysis of burden of disease and life expectancy. Lancet. 2012; 380(9838):219-229. https://doi.org/10.1016/s0140-6736(12)61031-9

[10] McPhee JS, French DP, Jackson D, Nazroo J, Pendleton N, Degens H. Physical activity in older age: perspectives for healthy ageing and frailty. Biogerontology. 2016; 17(3):567-580. https://doi.org/10.1007/s10522-016-9641-0

[11] Korea Employment Information Service (KEIS). Korean Longitudinal Study of Ageing. 2015; http:// survey.keis.or.kr/eng/klosa/klosa01.jsp. (Accessed March 8, 2017)

[12] The Ministry of Health and Welfare. The Physical Activity Guide for Koreans. 2013; http://health.mw.go.kr/ReferenceRoomArea/ HealthFileRoom/healthFileDetail.do?ED_NO=1851. (Accessed October 31, 2016)

[13] Kim J-M, Shin I-S, Yoon J-S, Lee H-Y. Comparison of diagnostic validities between MMSE-K and KMMSE for screening of dementia. J Korean Neuropsychiatr Asso. 2003; 42(1):124-130.

[14] Folstein MF, Folstein SE, McHugh PR. "Mini-mental state". A practical method for grading the cognitive state of patients for the clinician. J Psychiatr Res. 1975; 12(3):189-198.

[15] Jang JY, Kim J. Association between handgrip strength and cognitive impairment in elderly Koreans: a population-based cross-sectional study. J Phys Ther Sci. 2015; 27(12):3911-3915. https://doi.org/10.1589/jpts.27.3911

[16] Huang CY, Hwang AC, Liu LK, et al. Association of dynapenia, sarcopenia and cognitive impairment among community-dwelling older Taiwanese. Rejuvenation Res. 2015; 19(1):71-78. https://doi.org/10.1089/rej.2015.1710

[17] Rosano C, Simonsick EM, Harris TB, et al. Association between physical and cognitive function in healthy elderly: the health, aging and body composition study. Neuroepidemiology. 2005; 24(1-2):8-14. https://doi.org/10.1159/000081043

[18] Sandroff BM, Pilutti LA, Benedict RH, Motl RW. Association between physical fitness and cognitive function in multiple sclerosis: does disability status matter? Neurorehabil Neural Repair. 2015; 29(3):214 -223. https://doi.org/10.1177/1545968314541331

[19] Blondell SJ, Hammersley-Mather R, Veerman JL. Does physical activity prevent cognitive decline and dementia?: A systematic review and meta-analysis of longitudinal studies. BMC Public Health. 2014; 14:510. https://doi.org/10.1186/1471-2458-14-510

[20] Phillips CB, Edwards JD, Andel R, Kilpatrick M. Dai- 
ly physical activity and cognitive function variability in older adults. J Aging Phys Act. 2015; 24(2):256-

267.

https://doi.org/10.1123/japa.2014-0222

[21] Sabia S, Dugravot A, Dartigues JF, et al. Physical activity, cognitive decline, and risk of dementia: 28 year follow-up of Whitehall II cohort study. BMJ. 2017; 357:j2709. https://doi.org/10.1136/bmj.j2709

[22] Baltes PB, Lindenberger U. Emergence of a powerful connection between sensory and cognitive functions across the adult life span: a new window to the study of cognitive aging? Psychol Aging. 1997; 12(1):12-21.

[23] Salthouse TA. The processing-speed theory of adult age differences in cognition. Psychol Rev. 1996; 103 (3):403-428.

[24] Mielke MM, Roberts RO, Savica R, et al. Assessing the temporal relationship between cognition and gait: slow gait predicts cognitive decline in the Mayo Clinic Study of Aging. J Gerontol A Biol Sci Med Sci. 2013; 68(8):929-937. https://doi.org/10.1093/gerona/gls256

[25] Auyeung TW, Lee JS, Kwok T, Woo J. Physical frailty predicts future cognitive decline - a four-year prospective study in 2737 cognitively normal older adults. J Nutr Health Aging. 2011; 15(8):690-694.

[26] Auyeung TW, Kwok T, Lee J, Leung PC, Leung J,
Woo J. Functional decline in cognitive impairment-the relationship between physical and cognitive function. Neuroepidemiology. 2008; 31(3):167-173. https://doi.org/10.1159/000154929

[27] Kim J. Longitudinal trend of prevalence of meeting physical activity guidelines among Korean adults. Exerc Med. 2017; 1:2. https://doi.org/10.26644/em.2017.002

[28] Cox EP, O'Dwyer N, Cook R, et al. Relationship between physical activity and cognitive function in apparently healthy young to middle-aged adults: A systematic review. J Sci Med Sport. 2015. 19(8):61628. https://doi.org/10.1016/j.jsams.2015.09.003

[29] Kelly ME, Loughrey D, Lawlor BA, Robertson IH, Walsh C, Brennan S. The impact of exercise on the cognitive functioning of healthy older adults: a systematic review and meta-analysis. Ageing Res Rev. 2014; 16:12-31. https://doi.org/10.1016/j.arr.2014.05.002

[30] Groot C, Hooghiemstra AM, Raijmakers PG, et al. The effect of physical activity on cognitive function in patients with dementia: A meta-analysis of randomized control trials. Ageing Res Rev. 2015; 25:1323. https://doi.org/10.1016/j.arr.2015.11.005 